\title{
(Passive Infrared) Proximity Motion Security System Based On (Automatic and Interrogation) Alert With Multi-Zone Multi Responsible Persons
}

\author{
Asmaa Khalaf Salman ${ }^{1}$, K. S Rajasekhar ${ }^{2}$ \\ ${ }^{1}$ Student, Department Electronics and communication, Signal Processing, University College of Engineering \& Technology \\ Acharya Nagarjuna University \\ ${ }^{2}$ Assistant Professor, Electronics and communication Engineering Department University College of Engineering \& Technology, \\ Acharya Nagarjuna University
}

\begin{abstract}
The embedded systems are very important in the field of systems management, control, and the remote control in all the different environments by using different media transport (wired and wireless). Where entered in all aspects of life. In this paper illustrates the system protection against prying, unauthorized, or who tries to theft, etc. the proposed system consists of the PIR sensors allow you to sense motion, almost always used to detect whether a human has moved in or out of the sensors range. They are small, inexpensive, low-power, easy to use and don't wear out. For that reason, they are commonly found in appliances and gadgets used in homes or businesses, and a signaling procedure based on make Call to the responsible person (proprietor and concerned authorities) using GSM (Global Systems for Mobile communications) technology. And make it able to hear all the voices inside the place (Zone Under interest) and then has the potential to identify who entered the (The protected area) to do the best role and timely reaction in order to prevent the (prying, theft) with different actions.GSM module for sending and receiving (Call and SMS (automatic and interrogation alert)) and buzzer for alarm. So that we can dominate for multi-zone (i.e. more protected areas) by using multi actions with multi Proprietor whether suppose there are somebody local securities which can monitor the interested area that surrounding by PIR sensors. For software this system using Arduino IDE for Arduino. The design is based on a standalone embedded system board Android at home.
\end{abstract}

Keywords: Security-System, motion sensor,Arduino microcontroller, GSM 900 Module, PIR (Passive Infrared)

\section{Introduction}

Over the years, many engineering fields like computer science, electronics, communication and Instrumentation technology, use sensors together in order to get better products and benefits. Obviously, it is a convincing fact that interdisciplinary efforts would lead to success because each field would overcome the limitations of the other. So, taking this as a motivation, an attempt is made here to develop an alternative method to provide security [1]. To reduce the crime rates in the society especially the crime of theft for Government institutions, and due to the increasingly rapid movement of people, that making them requires a security technology that has the characteristics of mobile technology in terms of getting information easily and quickly. This Paper mainly focuses on providing security when the user is away from home. SMS (Short Message Service) or calls are a GSM mobile technology that can perform remote communication wherever they are [2]. Through these facilities, messages and calling can send quickly, accurately and at a low cost. Mobile phone with SMS and call facilities will be very useful when applied to integrated security systems, where the information send by a security system and the information received by the user mobile phone in the form of SMS or call.

\section{Proposed System}

The block diagram in figure (1) comprises of the power supply section,(Robodo Mega 2560) board, GSM SIM900 Module,

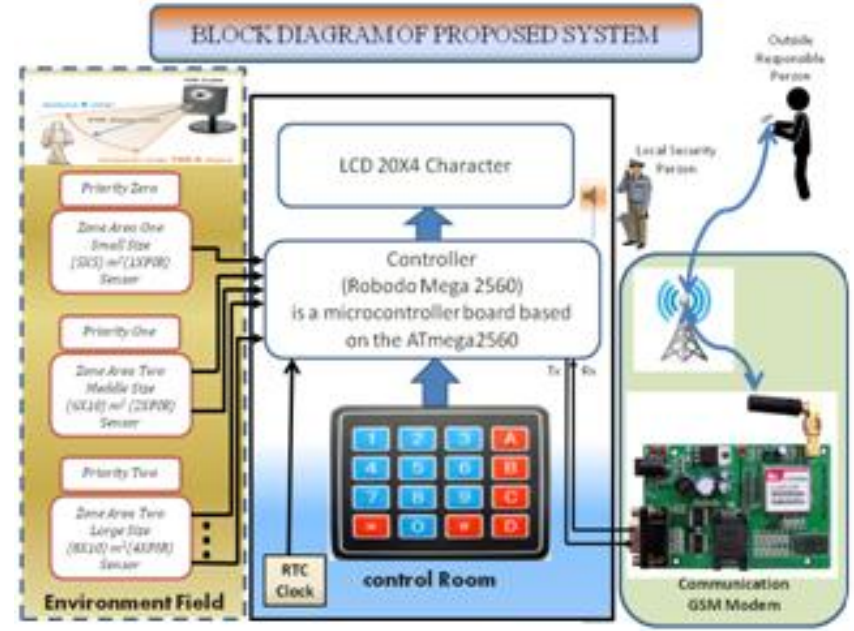

Figure 1: The system organized

PIR sensors to detect obstacle, with LCD 20X4, Buzzer alarm, Keypad $4 \mathrm{X} 4$. The circuit is powered through a step down transformer and the GSM modem using a 9-12 volts AC-to-DC adaptor. A valid SIM card with sufficient recharge amount must be inserted to the modem to make outgoing calls or messages. The system collects all information from 6 PIR sensors, process that informationand Call originates orsends SMS depend on Zone type and Priority to corresponding GSM mobile phonenumber by using a GSM modem. We use 6 PIRsensors for more accurate when detect obstacle at different areas with multi zone sensors. If PIR sensors detect any obstacle in coveredarea then the controller activate Buzzer alarm and Call originates orsend aSMS to the home proprietor mobile phone using the GSMModule shown in 


\section{International Journal of Science and Research (IJSR) \\ ISSN (Online): 2319-7064 \\ Index Copernicus Value (2013): 6.14 | Impact Factor (2014): 5.611}

Figure (1). The system organized inseveral units like controller, interfacing, GSM module andsensors.

\section{Hardware}

\subsection{PIR Sensor}

The PIR sensor is the core part of the system. The system basically function based on infrared radiation, which is emitted from human body. As shown in figure (2)
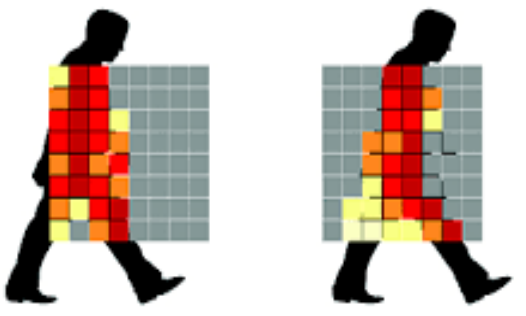

(a)

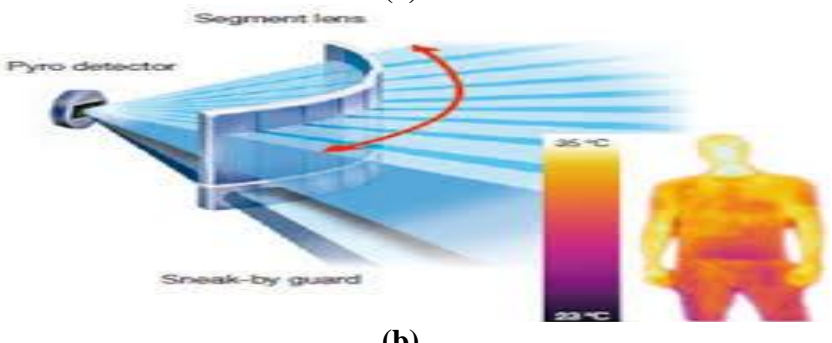

(b)

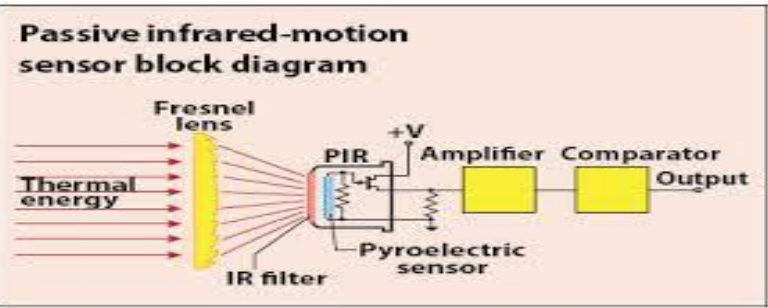

(c)

Figure 2:(a). Infrared Radiation of human body during movement. (b). Principal of PIRs Work. (c). Principal Block Diagram of PIR (Sensor).

PIR sensor is widely used in security system to detect the motion of human. Infrared (IR) light is electromagnetic radiation with a wavelength between 0.7 and 300 micrometers. Human beings are the source of infrared radiation. It was found that the normal human body temperature radiate IR at wavelengths of 10 micrometer to 12 micrometer. PIR sensors are passive electronic devices which detect motion by sensing infrared fluctuations such as in figure (2).

\subsection{How PIRs Work}

The PIR sensor itself has two slots in it each slot is made of a special material that is sensitive to IR as shown in figure (3). The lens used here is not really doing much and so we see that the two slots can 'see' out past some distance (basically the sensitivity of the sensor). When the sensor is idle, both slots detect the same amount of IR, the ambient amount radiated from the room or walls or outdoors. When a warm body like a human or animal passes by, it first intercepts one half of the PIR sensor, which causes a positive differential change between the two halves. When the warm body leaves the sensing area, the reverse happens, whereby the sensor generates a negative differential change. These change pulses are what is detected.
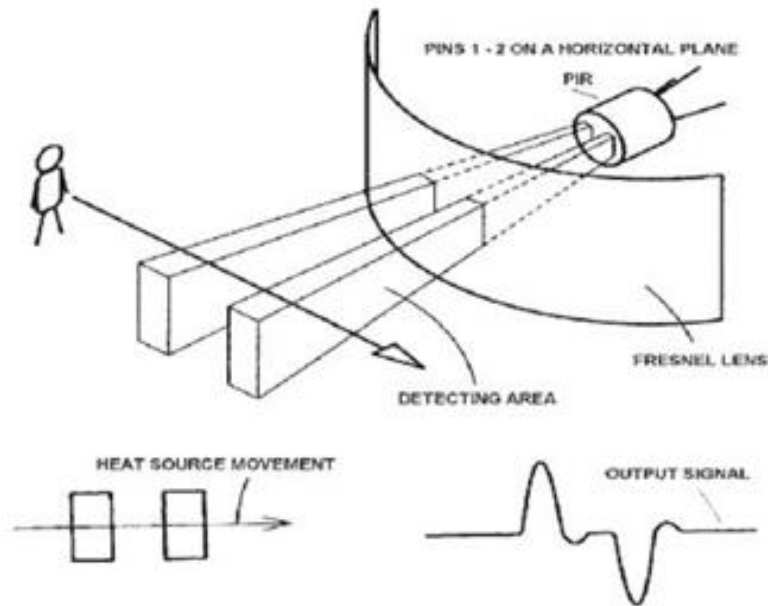

Figure 3: Principal of Work PIR (Sensor)

\subsection{Controller Unit}

\subsubsection{The board}

The Arduino Mega 2560 is a microcontroller board based on the ATmega2560 (datasheet). It has 54 digital input/output pins (of which 14 can be used as PWM outputs), 16 analog inputs, 4 UARTs (hardware serial ports), a $16 \mathrm{MHz}$ crystal oscillator, a USB connection, a power jack, an ICSP header, and a reset button. It contains everything needed to support themicrocontroller; simply connect it to a computer with a USB cable or power it with an AC-to-DC adapter or battery to get started. The Mega is compatible with most shields designed for the ArduinoDuemilanove or Diecimila

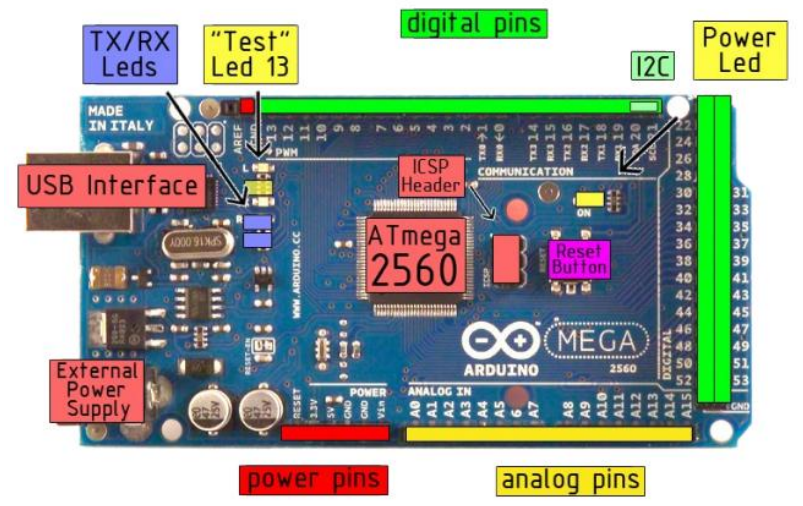

Figure 4: Arduino Mage 2560 Schematic

Table 11:Arduino Mage 2560 Input/output reference

\begin{tabular}{|c|c|}
\hline Microcontroller & ATmega2560 \\
\hline Operating Voltage & $5 \mathrm{~V}$ \\
\hline Input Voltage (recommended) & $6-12 \mathrm{~V}$ \\
\hline Input Voltage (limits) & $\begin{array}{c}\text { of } \\
\text { output) }\end{array}$ \\
\hline Digital I/O Pins & 16 \\
\hline Analog Input Pins & $40 \mathrm{~mA}$ \\
\hline DC Current per I/O Pin & $50 \mathrm{~mA}$ \\
\hline DC Current for 3.3V Pin & $\begin{array}{c}\text { (of which } 14 \text { ofrovide PWM } \\
\text { bootloader }\end{array}$ \\
\hline Flash Memory & $8 \mathrm{~KB}$ \\
\hline SRAM & $4 \mathrm{~KB}$ \\
\hline EEPROM & $16 \mathrm{MHz}$ \\
\hline Clock Speed & \\
\hline
\end{tabular}




\section{International Journal of Science and Research (IJSR) \\ ISSN (Online): 2319-7064}

Index Copernicus Value (2013): 6.14 | Impact Factor (2014): 5.611

\subsubsection{Power}

The power pins are as follows:

- VIN. The input voltage to the Arduino board when it's using an external power source (as opposed to 5 volts from the USB connection or other regulated power source). You can supply voltage through this pin, or, if supplying voltage via the power jack, access it through this pin.

- 5V. The regulated power supply used to power the microcontroller and other components on the board. This can come either from VIN via an on-board regulator, or be supplied by USB or another regulated 5V supply.

- 3V3. A 3.3 volt supply generated by the on-board regulator. Maximum current draw is $50 \mathrm{~mA}$. - GND. Ground pins.

\subsubsection{Memory}

The ATmega 2560 has $256 \mathrm{~KB}$ of flash memory for storing code (of which $8 \mathrm{~KB}$ is used for the bootloader), $8 \mathrm{~KB}$ of SRAM and $4 \mathrm{~KB}$ of EEPROM (which can be read and written with the EEPROM library)

\subsubsection{Input and Output}

Each of the 54 digital pins on the Mega can be used as an input or output, using pinMode(), digitalWrite(), and digitalRead() functions. They operate at 5 volts. Each pin can provide or receive a maximum of $40 \mathrm{~mA}$ and has an internal pull-up resistor (disconnected by default) of 20-50 kOhms. In addition, some pins have specialized functions:

- Serial: 0 (RX) and 1 (TX); Serial 1: 19 (RX) and 18 (TX); Serial 2: $17(\mathrm{RX})$ and $16(\mathrm{TX})$; Serial 3: $15(\mathrm{RX})$ and 14 (TX). Used to receive (RX) and transmit (TX) TTL serial data. Pins 0 and 1 are also connected to the corresponding pins of the ATmega8U2 USB-to-TTL Serial chip.

- External Interrupts: 2 (interrupt 0), 3 (interrupt 1), 18 (interrupt 5), 19 (interrupt 4), 20 (interrupt 3), and 21 (interrupt 2). These pins can be configured to trigger an interrupt on a low value, a rising or falling edge, or a change in value. See the attachInterrupt() function for details.

- PWM: 0 to 13. Provide 8-bit PWM output with the analogWrite() function.

- SPI: 50 (MISO), 51 (MOSI), 52 (SCK), 53 (SS). These pins support SPI communication, which, although provided by the underlying hardware, is not currently included in the Arduino language. The SPI pins are also broken out on the ICSP header, which is physically compatible with the Duemilanove and Diecimila.

- LED: 13. There is a built-in LED connected to digital pin 13. When the pin is HIGH value, the LED is on, when the pin is LOW, it's off.

- I 2C: 20 (SDA) and 21 (SCL). Support I2C (TWI) communication using the Wire library (documentation on the Wiring website). Note that these pins are not in the same location as the $\mathrm{I} 2 \mathrm{C}$ pins on the Duemilanove.

\subsection{Display}

$20 \times 4$ Characters LCD

FEATURES Type: Character

Display format: $20 \times 4$ characters

Built-in controller: ST 7066 (or equivalent)
Duty cycle: $1 / 16$

$5 \times 8$ dots includes cursor

$+5 \mathrm{~V}$ power supply (also available for $+3 \mathrm{~V}$ )

LED can be driven by pin 1, pin 2, pin 15 , pin 16 or A and $\mathrm{K}$ N.V. optional for $+3 \mathrm{~V}$ power supply

\subsection{Real-Time Clock}

The DS1307 Serial Real-Time Clock is a low-power, full binary-coded decimal (BCD) clock/calendar plus 56 bytes of NV SRAM. Address and data are transferred serially via a 2wire, bi-directional bus. The clock/calendar provides seconds, minutes, hours, day, date, month, and year information. The end of the month date is automatically adjusted for months with fewer than 31 days, including corrections for leap year. The clock operates in either the 24-hour or 12-hour format with AM/PM indicator. The DS1307 has a built-in power sense circuit that detects power failures and automatically switches to the battery supply [10].

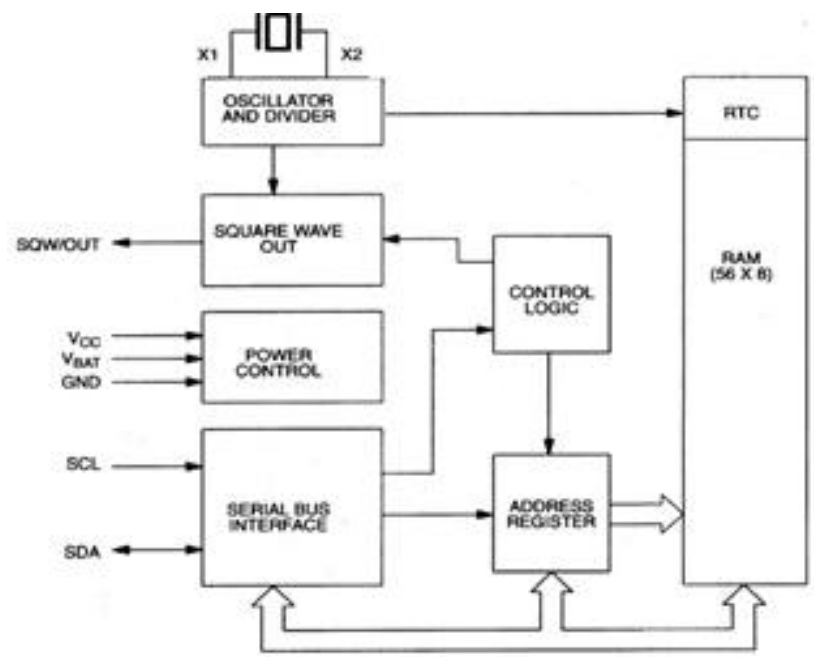

Figure 5: DS1307 Block Diagram

The DS1307 supports a bi-directional, 2-wire bus and data transmission protocol. A device that sends data onto the bus is defined as a transmitter and a device receiving data as a receiver. The device that controls the message is called a master. The devices that are controlled by the master are referred to as slaves. The bus must be controlled by a master device that generates the serial clock (SCL), controls the bus access, and generates the START and STOP conditions. The DS1307 operates as a slave on the 2- wire bus. A typical bus configuration using this 2-wire protocol is show in Figure $4[10]$.

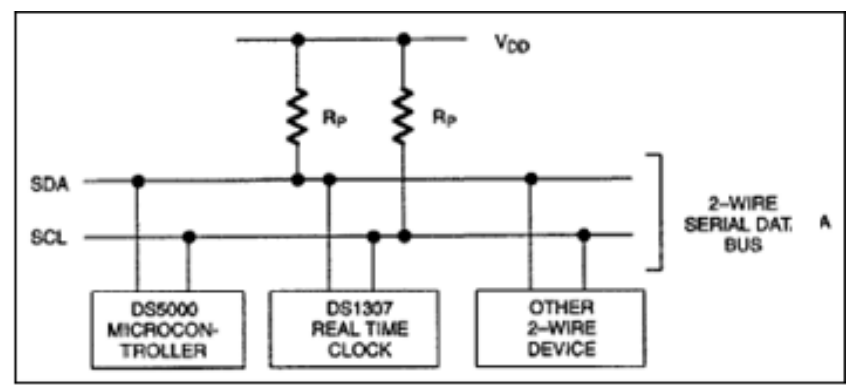

Figure 6: Typical 2-Wires Bus Configuration 


\section{International Journal of Science and Research (IJSR) \\ ISSN (Online): 2319-7064}

Index Copernicus Value (2013): 6.14 | Impact Factor (2014): 5.611

\subsection{Input Device}

4x4 Matrix Membrane Keypad

Matrix keypads use a combination of four rows and four columns to provide button states to the host device, typically a microcontroller. Underneath each key is a pushbutton, with one end connected to one row, and the other end connected to one column. These connections are shown in Figure 1.
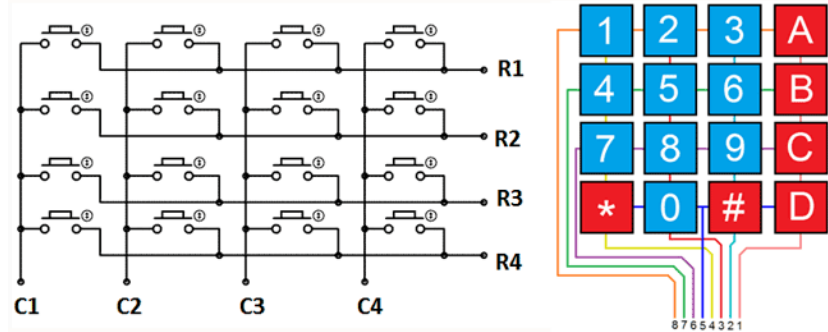

Figure 7: Matrix Keypad Connections

\subsection{Alarm Device}

\section{Buzzer alarm}

This is the DFRobot Buzzer Unit [9]. Through the Arduino, this unit will be able to control the buzzersounds. Used in combination with the Arduino boardsensors, to achieve the control of an interactive. Themodule pin definitions: 1 Output, 2 - Power Supply, 3 -ground. Module has interface socket for PH2.0 as shownin Figure 5. This unit can create sound by Arduinocontroller instruction.[9]

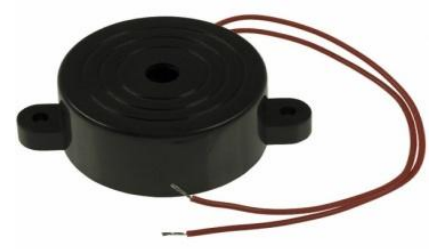

\section{Software Used}

The Arduino Integrated Development Environment (IDE) is a cross-platform application written in Java, and is derived from the IDE for the processing programming language and wiring projects. It is designed to introduce programming to artists unfamiliar with software development. It includes a code editor with features such as index highlighting, brace matching and automatic indentation. It is also capable of compiling and uploading programs to the board with a single click. Arduino programs are written in $\mathrm{C}$ or $\mathrm{C}++$. The Arduino IDE comes with a software library called „Wiring from the original wiring project, which makes many input/ output operations much easier. User only needs to define two functions to make a runnable cyclic executive program. As the Arduino platform uses Atmel microcontrollers, Atmel ${ }^{e e} s$ development environment, AVR studio or the newer Atmel studio may also be used for the development of software for Arduino [14].

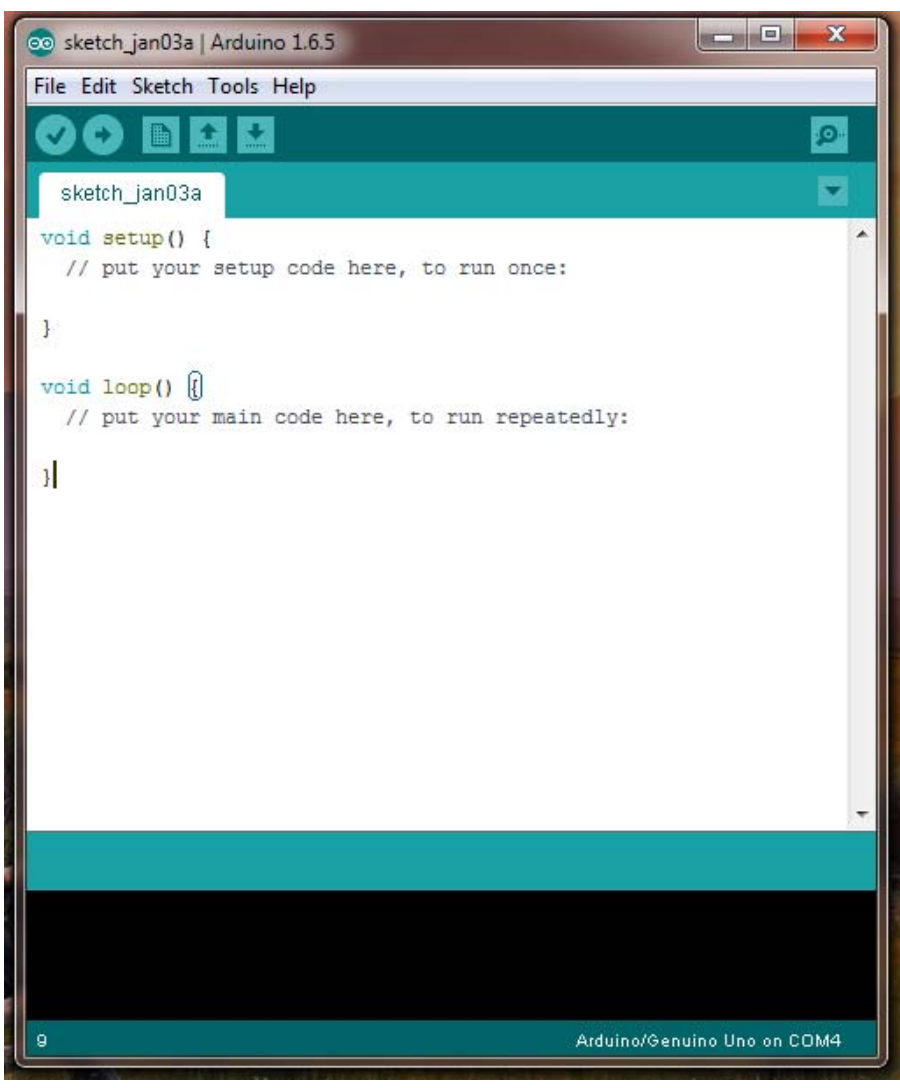

Figure 8: Arduino Integrated Development Environment (IDE)

\section{Conclusion}

Through this proposed system which act to limit the crime especially after that development which adds to it, we can provide different method to communicate with the responsible person of the interested area, and made him hear all the voice that happen inside the (inner zone) and identify the identification of the voice source which excited the system. Also we developed the system where covered multizone in different volumes subsequently we can covered different volume by using number of sensors depending on the features of the PIR .we developed the system to relay different alarms and alerts to different to different responsible persons such as local security and proprietor in such this case the system send initiate for them depending on the zone and the priority. Finally, we developed the latch algorithm to keep its state till the responsible person makes his decision for this situation after that can be reset the system (through using password) as well all these important features, the system based on using the GSM with its applications (i.e. SMS and Call) which become Known for all people, so it is available in low cost with multi types of sensors to provided this efficient application

\section{Future Scope}

By making a backup for the communication system in order to sensitive to the signal strong of the GSM antenna if its level decreased below the required level to secure communicates, in this case, the system will communicate with the responsible person in another way as (i.e. internet 


\section{International Journal of Science and Research (IJSR) \\ ISSN (Online): 2319-7064 \\ Index Copernicus Value (2013): 6.14 | Impact Factor (2014): 5.611}

service). Development the code by computing the energy that receives by PIR and drawing the histogram of this energy to determine the type of movement body. Finally, can be also development another system to test the function of the system during the maintenance time to check all facility of the system at good conditions.

\section{References}

[1] Kushal, V. ; Srikar, A.S. ; Srinivasan, K.” Photosensitive security system for theft detection and control using GSM technology"Signal Processing And Communication Engineering Systems (SPACES), 2015 International Conference on (Jan. 2015)

[2] Santoso Budijono1, Jeffri Andrianto2, Muhammad Axis Novradin Noor3" Design and implementation of modular home security system with short messaging system " published by EDP Sciences, 2014 EPJ Web of Conferences

[3] Ing. Jan Valouch, Integration of Alarm Systems, International Journal of Disaster Recovery and Business Continuity, Vol. 3, 2012.]

[4] Sheikh Izzal Azid, Bibhya Sharma, Intelligent Home: SMS Based Home Security System with Immediate Feedback, World Academy of Science, Engineering and Technology, Vol. 72, 2012.

[5] Mahendran.N, Geo Joe Mathai, Veenesh. M.U, Multiple Sensor Feeding Supported Building Automation System Using Arduino Platform With Exposure of 802.15.4 Functionalities, International Journal of Engineering Trends and Technology, Vol. 4 Issue2, 2013.

[6] Arduino website,http://arduino.cc/en/Main/arduinoBoardUno

[7] Simcom GSM modem website,http://www.simcom.eu/index.php?m=letoltes

[8] Seedstudio PIR sensor website, http://www.seeedstudio.com/wiki/File:TwigBISS0001.pd $f$

[9] DFRobot Buzzer Alarm website,www.dfrobot.com/wiki/index.php/Digital_Buzze r_Module_(SKU:_DFR0032)

[10] DFRobotRealtime clock website, http://www.dfrobot.com/wiki/index.php/Real_Time_Clo ck_Module_(DS1307)_(SKU:DFR0151)

[11] Md. Yusof H., Toha, S.F., Azlan N.Z., Zainuddin F., Muhida R., M. Kazim M.N.F, "Prototype Modeling of Security System with MetalDetector", Second IEEE Conference on IndustrialElectronics and Applications(2007).

[12] Qin Taichun, Li Xiaogang, Wang Yahui, Liu Ziwei, "Design of GSMbased Tele-Monitoring and Alarm System for Disposable Diaper", IEEE International Conference on Green Computing and Comuunications, 2013.

[13] Vinoth Kumar Sadagopan, Upendran Rajendran and Albert Joe Francis, "Anti Theft Control System Design Using Embedded System”, IEEE, 2011

[14] Arduino website, https://www.arduino.cc/

\section{Author Profile}

Asmaa Khalaf Salmanhave attained has B.Sc. in Electronics and communicationengineering from University of Technology-Baghdad in 2000. She is currently pursuing master's degree in Electronic and Communication Engineering in College of Engineering \& Technology, Acharya Nagarjuna University, Andhra Pradesh.

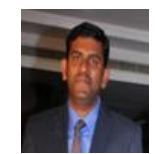

K S RajaSekhar received B.E degree in Electronics \& Instrumentation Technology from Visveswaraiaha Technological University, Belgaum, India and M. Tech in Embedded Systems from Vignan University, Guntur, India. Presently doing research work on hyperspectral imaging and working as assistant professor, Electronics and Communication Engineering Department in Acharya Nagarjuna University, Guntur 